\title{
C-Reactive Protein/Albumin Ratio Designates Advanced Heart Failure among Outpatients with Heart Failure
}

\author{
Oğuzhan Yücel, Hakan Günes', Murat Kerkütlüoglu', Mehmet Birhan Yılmaz² \\ Department of Cardiology, Near East University, Nicosia, 'Department of Cardiology, Faculty of Medicine, Kahramanmaraş Sütçü İmam University, Kahramanmaraş, \\ ²Department of Cardiology, Faculty of Medicine, Dokuz Eylül University, İzmir, Turkey \\ ORCID: \\ Oğuzhan Yücel: https://orcid.org/0000-0002-6076-9482 \\ Hakan Güneș: https://orcid.org/0000-0003-3853-5046 \\ Murat Kerkütlüoğlu: https://orcid.org/0000-0003-1007-0574 \\ Mehmet Birhan Yilmaz: https://orcid.org/0000-0002-8169-8628
}

\section{Abstract}

Background: Exercise intolerance has a relation with poor prognosis for patients with heart failure (HF). The high C-reactive protein (CRP) levels have prognostic effects on many cardiovascular diseases such as HF, coronary artery disease, and ischemic stroke. The low serum albumin levels are related with poor prognosis in patients with HF. We aimed to investigate whether the assessment of CRP/albumin ratio would enable clinicians to identify patients with advanced HF. Materials and Methods: This retrospective study included $102 \mathrm{HF}$ patients with reduced ejection fraction $(\leq 40 \%)$. The mean age of patients was $44 \pm 13$ years. Advanced HF (New York Heart Association [NYHA] Functional Class III-IV) was observed in 27 patients (26.5\%). Results: CRP/albumin ratio was on average higher in patients with NYHA functional Classes III and IV than in patients with NYHA functional Classes I and II $(0.4$ [0.02-1.97] vs. 0.12 [0.02-1.63], $P<0.001)$. In multiple logistic regression model with forward stepwise method, CRP/albumin ratio (odds ratio [OR]: 3.084, $P: 0.036,95.0 \%$ confidence interval [CI]: 1.074-3.855) and brain natriuretic peptide $>500 \mathrm{pg} / \mathrm{ml}$ (OR: 3.526, $P: 0.014,95.0 \%$ CI: 1.290-9.637) remained associated with advanced HF. Conclusions: For the first time in the literature, we showed that elevated CRP/albumin ratio was found to be independently associated with advanced HF. We have also shown that high CRP/albumin ratio was associated with poor hemodynamic parameters.

Keywords: Albumin, C-reactive protein, C-reactive protein/albumin ratio, heart failure with reduced ejection fraction, outpatients, poor functional capacity

\section{INTRODUCTION}

It is known that exercise intolerance has a relation with poor prognosis for patients with heart failure (HF). ${ }^{[1,2]}$ The New York Heart Association (NHYA) classification is the most widely used method to show the effect of HF on daily activities. It has been shown that patients in high NYHA classification are more frequently hospitalized, have worse life qualities, and lose their lives earlier. ${ }^{[3,4]}$ In a consensus report published by the European Society of Cardiology in 2018, NYHA Class 3-4 HF diagnosis of advanced functional capacity is said to be one of the most important parameters used. ${ }^{[5]}$

Received: 02-10-2019 Revised: 17-11-2019 Accepted: 28-01-2020

Published Online: 11-06-2020

\begin{tabular}{|l|l|}
\hline \multicolumn{3}{c|}{ Access this article online } \\
\hline Quick Response Code: & Website: \\
& \\
http://www.ijcva.com
\end{tabular}

C-reactive protein (CRP) is an acute-phase reactant and an indicator of chronic inflammation. ${ }^{[6]}$ It has been documented that the high CRP levels have prognostic and therapeutic effects on many cardiovascular diseases such as $\mathrm{HF},{ }^{[7]}$ coronary artery disease $(\mathrm{CAD}),{ }^{[8]}$ and ischemic stroke. ${ }^{[9]}$ Hypoalbuminemia is widely encountered in patients with $\mathrm{HF}$ and can give information about malnutrition and inflammatory situation. ${ }^{[10]}$ It has been shown that the low serum albumin levels are related with poor prognosis in patients with HF. ${ }^{[11,12]}$

Address for correspondence: Dr. Murat Kerkütlüoglu, Department of Cardiology, Faculty of Medicine, Kahramanmaras Sütçü Imam University, Kahramanmaras, Turkey. E-mail:drmuratkerk@gmail.com

This is an open access journal, and articles are distributed under the terms of the Creative Commons Attribution-NonCommercial-ShareAlike 4.0 License, which allows others to remix, tweak, and build upon the work non-commercially, as long as appropriate credit is given and the new creations are licensed under the identical terms.

For reprints contact: WKHLRPMedknow_reprints@wolterskluwer.com

How to cite this article: Yücel $\mathrm{O}$, Günes $\mathrm{H}$, Kerkütlüoglu M, Y1lmaz MB. $\mathrm{C}$-reactive protein/albumin ratio designates advanced heart failure among outpatients with heart failure. Int J Cardiovasc Acad 2020;6:51-6. 
The combination of these two parameters, namely the ratio of CRP to albumin, may have more value than either of them individually for predicting poor NYHA functional capacity in chronic HF. In this study, we aimed to investigate whether the assessment of CRP/albumin ratio would enable clinicians to identify patients with advanced HF.

\section{Materials and Methods}

\section{Patients}

In this retrospective study, 152 adult patients with left ventricular ejection fraction (LVEF) $\leq 40 \%$ were screened in the HF outpatient clinic. Patients with acute decompensated HF and new-onset HF; patients without albumin and CRP values at admission; and chronic renal failure patients with low albumin levels due to severe malnutrition, hematological disease, cancer, neoplastic metastases to bone marrow, sepsis, ongoing systemic inflammatory conditions, pregnancy, autoimmune disease, glucocorticoid therapy, acute myocardial ischemia, and cardiogenic shock were excluded from the study [Figure 1]. The study included $102 \mathrm{HF}$ patients (mean age: $44 \pm 13$ years) with reduced ejection fraction (EF) applying to our HF center. Patients were classified into two groups based on NYHA functional class. NYHA functional classification was determined by the cardiologists who were blinded to the clinical data of the patients. The study was approved by the local ethics committee under protocol number 2010-01/13. Written informed consent was acquired from each participant. The research was conducted in accordance with the principles specified in the Declaration of Helsinki.

All venous blood samples were obtained upon patient presentation. Blood samples for a complete blood count and serum chemistry including serum albumin and CRP levels were collected through peripheral vein. The measurement of CRP

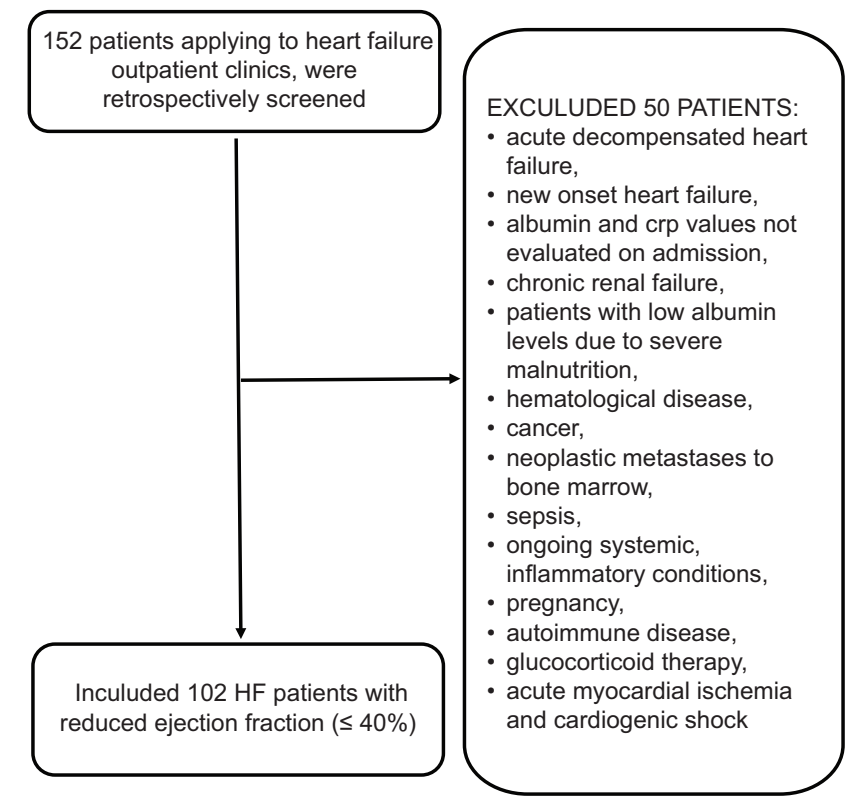

Figure 1: Flowchart shows the patient selection process was performed using CRP-Latex (II) immunoturbidimetric assay (Denka Seiken Co., Ltd., Tokyo, Japan). ${ }^{[13]}$

\section{Echocardiography}

Senior operators have carried out the echocardiography examinations. A system available in the mercantile (Vivid 7, General Electric Vingmed Ultrasound, Horten, Norway) was used to image the patients in the left lateral decubitus position. Making use of the parasternal long and short axes and apical and subcostal views, Doppler tracings, and two-dimensional images were attained. Left ventricles' internal dimensions and septum and posterior wall thicknesses were measured in two-dimensional guided M-mode at the LV minor axis. Simpson's biplane method was utilized for measuring LVEF. ${ }^{[14]}$

\section{Statistical analysis}

Continuous variables were expressed as mean \pm standard deviation or median ( $\min -\max )$ in the presence of abnormal distribution and categorical variables as percentages. Comparisons between groups of patients were made by the use of a Chi-square test for categorical variables, independent samples $t$-test for normally distributed continuous variables, and Mann-Whitney U-test when the distribution was skewed. Correlations were evaluated either through Pearson or Spearman correlation tests. We used univariate logistic regression analysis to quantify the association of advanced HF. Patients CRP, albumin, CRP/albumin ratio, sodium, brain natriuretic peptide (BNP) $>500 \mathrm{pg} / \mathrm{ml}$, hemoglobin, age, fasting glucose, alanine aminotransferase, aspartate aminotransferase, creatinine levels and diabetes mellitus, beta - blockers use, aldosterone antagonist use characteristics were evaluated with the multivariate logistic regression model with forward stepwise method to determine the independent prognostic factors of advanced HF. Receiver operator characteristic (ROC) curve analysis was performed to identify the optimal cutoff point of CRP/albumin ratio (at which sensitivity and specificity would be maximal) for the prediction of poor functional capacity. Areas under the curve (AUC) were calculated as measures of the accuracy of the tests. We compared the AUC with the use of the Z-test. All statistical procedures were performed using SPSS software version 14.0 (SPSS Inc., Chicago, IL, USA). $P=0.05$ was considered as statistically significant.

\section{RESULTS}

Considering the whole cohort, the mean age of patients was $44 \pm 13$ years $(85 \%$ - male and $15 \%$ - female $)$. The mean LVEF was $23 \pm 6 \%$, and the median CRP/albumin ratio was 0.15 (0.02-1.97). Advanced HF (NYHA Functional Class III-IV) was observed in 27 patients (26.5\%).

A comparison of two groups of patients with HF was summarized in Table 1. CRP/albumin ratio was on average higher in patients with NYHA functional Classes III and IV than in patients with NYHA functional Classes I and II (0.4 [0.02-1.97] vs. 0.12 [0.02-1.63], $P<0.001)$. Presence of $\mathrm{CAD}, \mathrm{CRP}$, albumin, $\mathrm{CRP} /$ albumin ratio, sodium, hemoglobin, and BNP levels differed significantly in relation to NYHA functional class groups [Table 1]. 


\begin{tabular}{|c|c|c|c|c|}
\hline Variable & All $(n=102)$ & NYHA I-II $(n=75 ; 73.5 \%)$ & NYHA III-IV ( $n=27 ; 26.5 \%)$ & $P$ \\
\hline \multicolumn{5}{|l|}{ Baseline characteristics } \\
\hline Mean age (years) & $44 \pm 13$ & $44 \pm 12$ & $46 \pm 14$ & 0.334 \\
\hline Male/female & $87 / 15$ & $63 / 12$ & $24 / 3$ & 0.754 \\
\hline Hypertension, $n(\%)$ & $37(36)$ & $30(40)$ & $7(26)$ & 0.284 \\
\hline Diabetes mellitus, $n(\%)$ & $18(18)$ & $13(17)$ & $5(19)$ & 1.000 \\
\hline CAD, $n(\%)$ & $84(82)$ & $57(76)$ & $26(96)$ & 0.042 \\
\hline Heart rate (beats/min) & $87 \pm 15$ & $86 \pm 14$ & $89 \pm 16$ & 0.262 \\
\hline Systolic blood pressure $(\mathrm{mmHg})$ & $119 \pm 19$ & $121 \pm 19$ & $114 \pm 18$ & 0.085 \\
\hline Diastolic blood pressure (mmHg) & $77 \pm 15$ & $78 \pm 13$ & $75 \pm 18$ & 0.292 \\
\hline Atrial fibrillation, $n(\%)$ & $11(11)$ & $9(12)$ & $2(7)$ & 0.723 \\
\hline LVEF (\%) & $23 \pm 6$ & $23 \pm 6$ & $21.5 \pm 7$ & 0.294 \\
\hline \multicolumn{5}{|l|}{ Laboratory findings } \\
\hline CRP & $0.6(0.1-7.1)$ & $0.5(0.1-7)$ & $1.7(0.1-7.1)$ & 0.004 \\
\hline Albumin & $4.4 \pm 0.5$ & $4.4 \pm 0.4$ & $4.2 \pm 0.4$ & 0.028 \\
\hline $\mathrm{CRP} /$ albumin ratio & $0.15(0.02-1.97)$ & $0.12(0.02-1.63)$ & $0.4(0.02-1.97)$ & 0.002 \\
\hline Fasting glucose (mg/dl) & $106 \pm 36$ & $105 \pm 35$ & $111 \pm 37$ & 0.468 \\
\hline Creatinine (mg/dl) & $1.0 \pm 0.3$ & $1.0 \pm 0.3$ & $1.1 \pm 0.3$ & 0.258 \\
\hline Sodium $(\mathrm{mEq} / \mathrm{L})$ & $139 \pm 3.5$ & $140 \pm 3$ & $138 \pm 4$ & 0.011 \\
\hline Potassium (mEq/L) & $4.6 \pm 0.5$ & $4.6 \pm 0.5$ & $4.5 \pm 0.5$ & 0.333 \\
\hline Hemoglobin (gr/dl) & $14 \pm 2$ & $14.1 \pm 2$ & $13.2 \pm 2$ & 0.031 \\
\hline Brain natriuretic peptide (pg/ml) & $399(2-4333)$ & $190(2-2470)$ & $1103(3-4333)$ & $<0.001$ \\
\hline Brain natriuretic peptide $>500 \mathrm{pg} / \mathrm{ml}, n(\%)$ & $43(43)$ & $24(33)$ & $19(70)$ & 0.002 \\
\hline Total cholesterol (mg/dl) & $175 \pm 51$ & $181 \pm 46$ & $158 \pm 61$ & 0.079 \\
\hline Alanine aminotransferase (IU/L) & $37 \pm 52$ & $34 \pm 25$ & $46 \pm 93$ & 0.515 \\
\hline Aspartate aminotransferase (IU/L) & $31 \pm 25$ & $30 \pm 13$ & $35 \pm 44$ & 0.551 \\
\hline \multicolumn{5}{|l|}{ Medication, $n(\%)$} \\
\hline Antiplatelet agents & $47(46)$ & $34(45)$ & $13(48)$ & 0.979 \\
\hline Beta-blockers & $94(92)$ & $69(92)$ & $25(93)$ & 1.000 \\
\hline ACE inhibitor/ARB & $70(69)$ & $51(68)$ & $19(70)$ & 1.000 \\
\hline Digoxine & $45(44)$ & $30(40)$ & $15(56)$ & 0.242 \\
\hline Diuretics & $57(56)$ & $40(53)$ & $17(63)$ & 0.523 \\
\hline Aldosterone antagonist & $60(59)$ & $43(57)$ & $17(63)$ & 0.778 \\
\hline
\end{tabular}

ACE: Angiotensin-converting enzyme, ARB: Angiotensin receptor blocker, NYHA: New York Heart Association, CAD: Coronary artery disease,

LVEF: Left ventricular ejection fraction, CRP: C-reactive protein

$\mathrm{CRP} /$ albumin ratio was correlated with $\mathrm{CRP}$, albumin, $\mathrm{BNP}$, sodium, alanine aminotransferase, aspartate aminotransferase, creatinine, hemoglobin, and fasting glucose levels, age, presence of diabetes mellitus, beta-blockers, and aldosterone antagonist usage [Table 2].

Univariate and multiple logistic regression analyses for identifying poor NYHA functional class were listed in Table 3. CRP, albumin, CRP/albumin ratio, sodium, hemoglobin, and $\mathrm{BNP}>500 \mathrm{pg} / \mathrm{ml}$ were found to designate poor NYHA functional class. In multiple logistic regression model with forward stepwise method, CRP/albumin ratio (odds ratio [OR]: $3.084, P: 0.036,95.0 \%$ confidence interval [CI]: 1.074-3.855) and $\mathrm{BNP}>500 \mathrm{pg} / \mathrm{ml}$ (OR: 3.526, P: 0.014, 95.0\% CI: 1.290-9.637) remained associated with advanced HF after adjustment for variables found to be statistically significant in univariate analysis and correlated with CRP/ albumin ratio.

According to the ROC curve analysis, the optimal cutoff value of CRP/albumin ratio to predict advanced HF was found as $>0.15$, with $74 \%$ sensitivity and $61 \%$ specificity [AUC: 0.700, 95\% CI: 0.601-0.787, Figure 2].

\section{Discussion}

Although new treatment methods have been developed, HF still has a poor prognosis. ${ }^{[15]}$ Lots of factors have been shown to predict the poor prognosis, and the most important of those is the frequency of hospitalization. ${ }^{[16]}$ The most significant indicator of hospitalization is, in turn, the worsening functional capacity. ${ }^{[16]}$ By the way, the determination of the clinical and laboratory parameters which can make us predict will have a contribution to ameliorate the prognosis.

High levels of CRP in HF are caused by cardiac decompensation and damage to the other organs due to low cardiac output and venous congestion. Previous studies have also shown that inflammatory markers are elevated in patients with HF. CRP has been shown to increase in patients with $\mathrm{HF}$ and is associated with the severity of HF and increased cardiovascular mortality during follow-up. ${ }^{[17,18]}$ It is known that the inflammation in HF 
patients is related both with bad prognosis and bad functional capacity. ${ }^{[10-12]}$ In our study, CRP levels were found to be correlated with functional capacity.

Hypoalbuminemia is one of the most important indicators of malnutrition. Moreover, serum albumin level, which is a negative acute-phase reactant, decreases secondary to inflammation in HF. In addition, it has been shown that the increasing CRP levels and decreasing albumin levels are also interrelated. ${ }^{[19]}$ In our study, serum albumin levels were found to be related to functional capacity in patients with HF, similar to the literature.

In recent studies, it has been shown that the combination of those two parameters can be used as a strong prognostic

\begin{tabular}{lcc}
\hline $\begin{array}{l}\text { Table 2: Correlation coefficients for C-reactive } \\
\text { protein/albumin ratio }\end{array}$ & \\
\hline & $\boldsymbol{R}$ & $\boldsymbol{P}$ \\
\hline CRP & 0.992 & $<0.001$ \\
Brain natriuretic peptide $(\mathrm{pg} / \mathrm{ml})$ & 0.356 & $<0.001$ \\
Brain natriuretic peptide $>500 \mathrm{pg} / \mathrm{ml}$ & 0.429 & $<0.001$ \\
Age (years) & 0.334 & 0.001 \\
Sodium (mEq/L) & -0.312 & 0.001 \\
Beta-blocker usage & -0.289 & 0.003 \\
Alanine aminotransferase (IU/L) & -0.280 & 0.004 \\
Aspartate aminotransferase (IU/L) & -0.248 & 0.012 \\
Presence of diabetes mellitus & 0.242 & 0.014 \\
Creatinine (mg/dl) & 0.236 & 0.017 \\
Albumin & -0.219 & 0.027 \\
Aldosterone antagonist usage & -0.218 & 0.028 \\
Hemoglobin (gr/dl) & -0.215 & 0.030 \\
Fasting glucose (mg/dl) & 0.214 & 0.031 \\
\hline
\end{tabular}

CRP: C-reactive protein marker for mortality in older adults admitted to the emergency department and in acute kidney failure, sepsis, and cancer. ${ }^{[20-23]}$ In addition, the CRP/albumin ratio in patients with acute coronary syndrome has been shown to be related to the severity of CAD. ${ }^{[24]}$ Inflammation is a fundamental characteristic of HF, and CRP/albumin ratio might better reflect the inflammatory status; thus, we investigated the possible relationship between the functional capacity in $\mathrm{HF}$ and $\mathrm{CRP} /$ albumin ratio. We found that $\mathrm{CRP} /$ albumin ratio was an independent predictor of functional capacity in $\mathrm{HF}$, and the predictive accuracy of

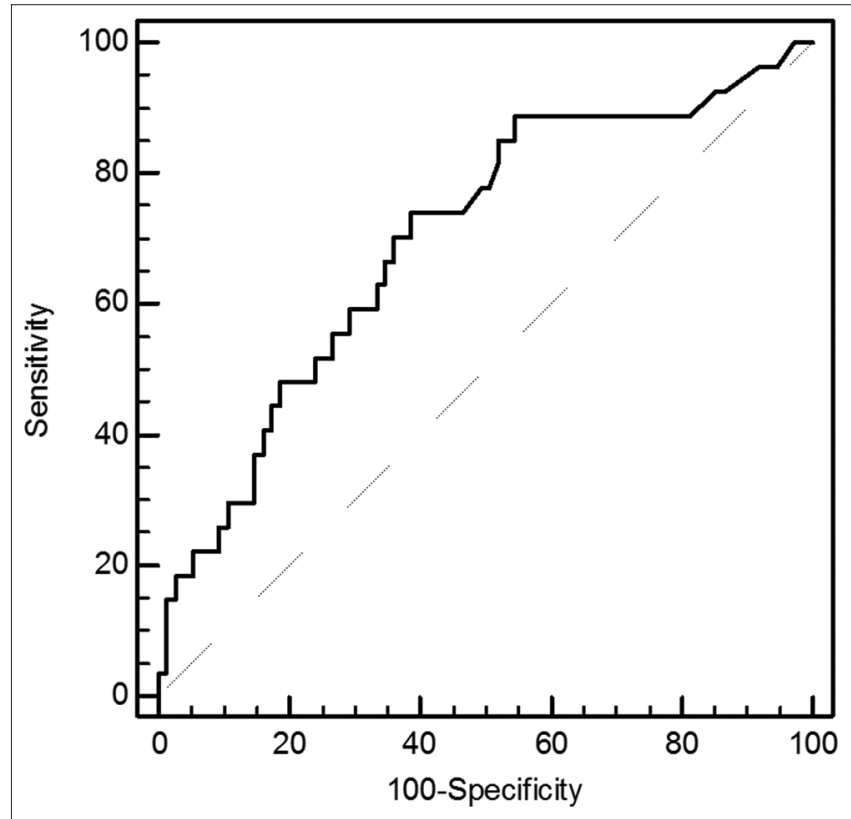

Figure 2: Receiver operator characteristic curve of C-reactive protein/ albumin ratio to predict advanced heart failure

\begin{tabular}{|c|c|c|c|c|c|c|}
\hline \multirow[t]{2}{*}{ Variable } & \multicolumn{3}{|c|}{ Univariate } & \multicolumn{3}{|c|}{ Multivariate } \\
\hline & $P$ & OR & $95 \% \mathrm{Cl}$ & $P$ & OR & $95 \% \mathrm{Cl}$ \\
\hline \multicolumn{7}{|l|}{ Statistically significant variables } \\
\hline CRP & 0.008 & 1.370 & $1.085-1.729$ & & & \\
\hline Albumin & 0.035 & 0.360 & $0.139-0.933$ & & & \\
\hline $\mathrm{CRP} /$ albumin ratio & 0.004 & 4.296 & $1.589-11.612$ & 0.036 & 3.084 & $1.074-3.855$ \\
\hline Sodium $(\mathrm{mEq} / \mathrm{L})$ & 0.015 & 0.846 & $0.740-0.968$ & & & \\
\hline Brain natriuretic peptide $>500 \mathrm{pg} / \mathrm{ml}$ & 0.001 & 4.750 & $1.818-12.411$ & 0.014 & 3.526 & $1.290-9.637$ \\
\hline Hemoglobin (gr/dl) & 0.035 & 0.764 & $0.595-0.981$ & & & \\
\hline \multicolumn{7}{|c|}{ Variables which correlated with $\mathrm{CRP} /$ albumin ratio } \\
\hline Age (years) & 0.332 & 1.018 & $0.982-1.056$ & & & \\
\hline Beta-blocker usage & 0.922 & 1.087 & $0.206-5.742$ & & & \\
\hline Alanine aminotransferase (IU/L) & 0.334 & 1.004 & $0.996-1.012$ & & & \\
\hline Aspartate aminotransferase (IU/L) & 0.376 & 1.007 & 0.991-1.024 & & & \\
\hline Presence of diabetes mellitus & 0.890 & 1.084 & $0.347-3.390$ & & & \\
\hline Creatinine (mg/dl) & 0.258 & 2.314 & $0.541-9.905$ & & & \\
\hline Aldosterone antagonist usage & 0.611 & 1.265 & $0.512-3.128$ & & & \\
\hline Fasting glucose $(\mathrm{mg} / \mathrm{dl})$ & 0.466 & 1.004 & 0.993-1.016 & & & \\
\hline
\end{tabular}

All the variables from Table 1 were examined, and only those significant at a $P<0.05$ level and those with a correlated CRP/albumin ratio level are shown in univariate analysis. The multiple logistic regression model included all univariate predictors and those with correlated CRP/albumin ratio level. CI: Confidence interval, OR: Odds ratio, CRP: C-reactive protein 
$\mathrm{CRP} /$ albumin ratio was better than that of CRP and albumin level, as per the comparison of the ROC curves. Furthermore, in our present study, we have documented that the CRP/albumin ratio is strongly positively correlated with BNP level which is an indicator of left ventricular filling pressure. Furthermore, we have shown that the patients having high CRP/albumin ratio are hyponatremic and anemic and have bad kidney functionalities. Hence, we think that $\mathrm{CRP} /$ albumin ratio seems to reflect the increasing severity of $\mathrm{HF}$.

\section{Limitations}

Our study has certain limitations. First, the other inflammatory markers which are not part of the routine evaluation were not analyzed. In addition, this study was carried out with a small number of Turkish patients. However, on the contrary, the objective evaluation of functional status on top of NYHA has potentially increased the value of the findings. The second limitation was that the NHYA classification inevitably included subjective judgments of symptoms and clinical data, and variability between the interobservers and intraobservers has been widely reported. Various psychological and environmental factors can influence the functional status, and adherence to the therapy is affected by cognitive factors and patient attitude. In addition, some genre of functional assessments such as cardiopulmonary exercise test or 6-min walk test was not performed. The final limitation was that our study included only patients with impaired EF (LVEF <0.40); hence, our results cannot be extrapolated to the population of patients with $\mathrm{HF}$ and preserved EF.

\section{Conclusions}

For the first time in the literature, we showed that, in the presence of the other clinical and laboratory parameters, elevated CRP/albumin ratio was found to be independently associated with advanced HF. We have also shown that high $\mathrm{CRP} /$ albumin ratio was associated with poor hemodynamic parameters. Our study showed that this simple and widely available test might help to identify HF patients who are at a higher risk of hospitalization and may help risk stratification of these patients.

\section{Financial support and sponsorship}

Nil.

\section{Conflicts of interest}

There are no conflicts of interest.

\section{References}

1. Bittner $\mathrm{V}$, Weiner $\mathrm{DH}$, Yusuf $\mathrm{S}$, Rogers WJ, McIntyre KM, Bangdiwala SI, et al. Prediction of mortality and morbidity with a 6-minute walk test in patients with left ventricular dysfunction. SOLVD Investigators. JAMA 1993;270:1702-7.

2. Piepoli MF, Corrà U, Agostoni P. Cardiopulmonary exercise testing in patients with heart failure with specific comorbidities. Ann Am Thorac Soc 2017;14:S110-5.

3. Bennett JA, Riegel B, Bittner V, Nichols J. Validity and reliability of the NYHA classes for measuring research outcomes in patients with cardiac disease. Heart Lung 2002;31:262-70.

4. Givi M, Shafie D, Nouri F, Garakyaraghi M, Yadegarfar G, Sarrafzadegan N. Survival rate and predictors of mortality in patients hospitalised with heart failure: A cohort study on the data of Persian registry of cardiovascular disease (PROVE). Postgrad Med J 2018;94:318-24

5. Crespo-Leiro MG, Metra M, Lund LH, Milicic D, Costanzo MR, Filippatos G, et al. Advanced heart failure: A position statement of the Heart Failure Association of the European Society of Cardiology. Eur J Heart Fail 2018;20:1505-35.

6. Danesh J, Wheeler JG, Hirschfield GM, Eda S, Eiriksdottir G, Rumley A, et al. C-reactive protein and other circulating markers of inflammation in the prediction of coronary heart disease. N Engl J Med 2004;350:1387-97.

7. Kardys I, Knetsch AM, Bleumink GS, Deckers JW, Hofman A, Stricker BH, et al. C-reactive protein and risk of heart failure. The rotterdam study. Am Heart J 2006;152:514-20.

8. Kavsak PA, MacRae AR, Newman AM, Lustig V, Palomaki GE, Ko DT, et al. Elevated C-reactive protein in acute coronary syndrome presentation is an independent predictor of long-term mortality and heart failure. Clin Biochem 2007;40:326-9.

9. Gussekloo J, Schaap MC, Frölich M, Blauw GJ, Westendorp RG. C-reactive protein is a strong but nonspecific risk factor of fatal stroke in elderly persons. Arterioscler Thromb Vasc Biol 2000;20:1047-51.

10. Pasini E, Aquilani R, Gheorghiade M, Dioguardi FS. Malnutrition, muscle wasting and cachexia in chronic heart failure: The nutritional approach. Ital Heart J 2003;4:232-5.

11. Horwich TB, Kalantar-Zadeh K, MacLellan RW, Fonarow GC. Albumin levels predict survival in patients with systolic heart failure. Am Heart J 2008; $155: 883-9$

12. Uthamalingam S, Kandala J, Daley M, Patvardhan E, Capodilupo R, Moore SA, et al. Serum albumin and mortality in acutely decompensated heart failure. Am Heart J 2010;160:1149-55.

13. Roberts WL, Moulton L, Law TC, Farrow G, Cooper-Anderson M, Savory J, et al. Evaluation of nine automated high-sensitivity C-reactive protein methods: İmplications for clinical and epidemiological applications. Part 2. Clin Chem 2001;47:418-25.

14. Lang RM, Badano LP, Mor-Avi V, Afilalo J, Armstrong A, Ernande L, et al. Recommendations for cardiac chamber quantification by echocardiography in adults: An update from the American Society of Echocardiography and the European Association of Cardiovascular Imaging. J Am Soc Echocardiogr 2015;28:1-3.9E+15.

15. Ponikowski P, Voors AA, Anker SD, Bueno H, Cleland JG, Coats AJ, et al. 2016 ESC Guidelines for the diagnosis and treatment of acute and chronic heart failure: The Task Force for the diagnosis and treatment of acute and chronic heart failure of the European Society of Cardiology (ESC). Developed with the special contribution of the Heart Failure Association (HFA) of the ESC. Eur J Heart Fail 2016;18:891-975.

16. Ahmed A, Allman RM, Fonarow GC, Love TE, Zannad F, Dell'italia LJ, et al. Incident heart failure hospitalization and subsequent mortality in chronic heart failure: A propensity-matched study. J Card Fail 2008;14:211-8.

17. Tsutamoto T, Hisanaga T, Wada A, Maeda K, Ohnishi M, Fukai D, et al. Interleukin-6 spillover in the peripheral circulation increases with the severity of heart failure, and the high plasma level of interleukin-6 is an important prognostic predictor in patients with congestive heart failure. J Am Coll Cardiol 1998;31:391-8.

18. Rauchhaus M, Doehner W, Francis DP, Davos C, Kemp M, Liebenthal C, et al. Plasma cytokine parameters and mortality in patients with chronic heart failure. Circulation 2000;102:3060-7.

19. Hannan JL, Radwany SM, Albanese T. In-hospital mortality in patients older than 60 years with very low albumin levels. J Pain Symptom Manage 2012;43:631-7.

20. Oh J, Kim SH, Park KN, Oh SH, Kim YM, Kim HJ, et al. High-sensitivity C-reactive protein/albumin ratio as a predictor of in-hospital mortality in older adults admitted to the emergency department. Clin Exp Emerg Med 2017;4:19-24.

21. Xie Q, Zhou Y, Xu Z, Yang Y, Kuang D, You H, et al. The ratio of CRP to prealbumin levels predict mortality in patients with hospital-acquired 
acute kidney injury. BMC Nephrol 2011;12:30.

22. Ranzani OT, Zampieri FG, Forte DN, Azevedo LC, Park M. C-reactive protein/albumin ratio predicts 90 -day mortality of septic patients. PLoS One 2013;8:e59321.

23. Li YJ, Yao K, Lu MX, Zhang WB, Xiao C, Tu CQ. Prognostic value of the C-reactive protein to albumin ratio: A novel inflammation-based prognostic indicator in osteosarcoma. Onco Targets Ther 2017;10:5255-61.

24. Çağdaş M, Rencüzoğullari I, Karakoyun S, Karabă g, Yesin M, Artaç I, et al. Assessment of relationship between C-reactive protein to albumin ratio and coronary artery disease severity in patients with acute coronary syndrome. Angiology 2019;70:361-8. 